Mechanical Engineering Design: An Introduction 


\title{
MECHANICAL ENGINEERING DESIGN
}

\section{An Introduction}

\author{
G. D. REDFORD \\ C.Eng., A.M.I.Mech.E., A.M.I.E.D. \\ Senior Lecturer in Mechanical Engineering \\ Wigan and District Mining and Technical College
}

Macmillan Education 


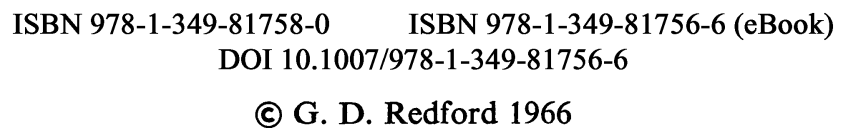

Softcover reprint of the hardcover 1st edition 1966 978-0-333-03322-7

First published 1966

Medium 8vo, xii + 446 pages

412 line illustrations

8 half tones

30 tables

MACMILLAN AND COMPANY LIMITED

Incorporating Cleaver-Hume Press Limited

Little Essex Street London WC2

also Bombay Calcutta Madras Melbourne

THE MACMILLAN COMPANY OF CANADA LIMITED

70 Bond Street Toronto 2

ST. MARTIN'S PRESS INC

175 Fifth Avenue New York NY 10010 


\section{Acknowledgements}

$\mathrm{T}$

HE Author wishes to acknowledge the assistance he has received from the following organisations and representatives, who have given him permission to publish information concerning the particular products with which they are associated. Other individual acknowledgements are to be found in the book where relevant. Access Equipment Ltd; Automotive Products Co. Ltd; The British Standards Institution; British Timken; The Butler Machine Tool Co. Ltd; Coley Bros. (Tools) Ltd; Dane Electrical Controls Ltd; Dowty Hydraulic Units Ltd; B. Elliott (Machinery) Ltd; J. H. Fenner \& Co. Ltd; Hoffman Manufacturing Co. Ltd; The Institution of Mechanical Engineers; Leyland Motors Ltd; J. McInnes Esq., County Surveyor and Bridgemaster to the Westmorland County Council; Pioneer Oilsealing \& Moulding Co. Ltd; Rozalex Ltd; Small \& Parkes Ltd; Messrs. Stevenson-Ward, Consultant Designers; Stewarts \& Lloyds Ltd; Taylor Industrial Clutches Ltd; H. Terry \& Sons Ltd; A. G. Thornton Ltd; The Union of Lancashire \& Cheshire Institutes; Alfred Wiseman \& Co. Ltd.

In conclusion, I wish to thank Mrs. B. Marsh and Mrs. M. Robinson who so kindly prepared the typescript and Miss G. Tyldesley who traced the drawings. I am also grateful to the publishers for the help and advice given at various stages in the preparation of the book, and to my wife for her assistance in reading the proofs. 


\section{Preface}

$\mathrm{D}$

URING recent years there has been a growing belief in industrial and educational fields that engineering design, as a highly important aspect of our industrial economy, merits far greater attention than it has hitherto received. This belief has been strengthened by the report of the Feilden Committee on Engineering Design and has already resulted in the addition of Engineering Drawing and Design to the Ordinary National Certificate Courses in Mechanical Engineering and to the inclusion of Mechanical Engineering Design by the Institution of Mechanical Engineers as a Part II subject for exemption from the Institution's Examinations for Associate Membership.

This book has been written partly in anticipation of such changes and partly to meet the requirements of existing syllabuses relating to Engineering Design in Part I of Degree, Higher National Diploma and fifth and sixth year Technician's Courses. In addition it is hoped that it will form a useful work of reference for design office personnel.

The contents have been arranged so that the earlier chapters provide the reader with general background information against which the designs given later can be set. These are graded in complexity to illustrate component design and then the design of simple assemblies. The final chapter carries the work to a logical conclusion in providing a design analysis of a complete machine tool.

My thanks are due to those manufacturers and representatives of various organisations who have so kindly allowed me to interpret their products in a manner suitable for text-book presentation, or have provided me with information of a more general nature. The products used as design examples were chosen for their creative content and interesting industrial features, and as embodying many of the principles of strength of materials, theory of machines and other related subjects. In many instances the manufacturer's own design calculations must have involved more detailed consideration than was possible in a book of this kind. I trust that where this is so my interpretation has not been too unfair. Generally the designs have been worked to slide rule order of accuracy since practical considerations have frequently intruded to necessitate the 'rounding off' of dimensions to standard sizes. Where thought necessary, logarithmic tables have been used.

G. D. REDFORD 


\section{Contents}

PREFACE

vii

I Characteristics of Modern Materials

1. Choice of Materials. 2. Ferrous Metals. 3. Non-Ferrous Metals. 4. Plastics.

II Aspects of Economic Production

1. Influence of Production Methods on Design. 2. Designing for Forming Processes: Casting. 3. Designing for Forming Processes: Hot Working. 4. The Economics of Shape.

III Types of Stresses

1. The Significance of Stress. 2. Direct and Indirect Stresses.

3. Stresses Caused by Bending. 4. Stresses Caused by Torsion.

5. Compound Stresses.

IV Corrosion, Fatigue and Creep

1. Their Relevance for Design. 2. Corrosion. 3. Designing to Defeat Corrosion. 4. Fatigue. 5. Designing to Avoid Fatigue Failure. 6. Creep.

\section{Standard Components}

1. Keys and Keyways. 2. Fluid Seals. 3. Hollow Sections. 4. V-Belts. 5. Bearings.

\section{Aesthetic and Ergonomic Considerations}

1. Appearance Design. 2. The Contribution of Ergonomics to Good Design. 3. The Contribution of Art to Good Design. 4. The Co-ordination of Function and Appearance. 5. Selected Designs: No. 1. The MS 44 Universal Spring Pencil Compass. No. 2. The Anglepoise Lamp. No. 3. The Elliott Omnitool High Precision Lathe. 
1. Principles: Introduction, Notation, Basic Relationships in Simple Stress, Stress Terminology. 2. Designs : No. 1. Hydraulically Operated Clamps. No. 2. Cast Iron Ribbed Cover Plate. No. 3. Forged Steel Exhaust Valve Lever. No. 4. Aircraft Component of Solid Circular Cross-Section. No. 5. Drop Forged Steel Connecting Rod. 3. Examples (eight).

\section{Components Subjected to Bending and Direct Stress : Unsymmetrical Bending}

1. Principles: The Causes of Combined Bending and Direct Stress, Notation, Symmetrical Bending and Direct Stress, Unsymmetrical Bending. 2. Designs: No. 1. Mandrel Press. No. 2. Forked Rod End. No. 3. Press Frame. No. 4. Supporting Structure for Water Storage Tank. No. 5. Forged Steel Haulage Link. 3. Examples (five).

\section{Components under Torsion and Combined} Bending and Torsion

1. Principles: Preliminary Considerations, Notation and Formulae, 2. Designs: No. 1. Simple Shaft with Flanged Coupling. No. 2. Shaft for Overhead Lift Gear. No. 3. Light Alloy Lever. No. 4. Crankshaft for Single Cylinder Engine. No. 5. Machine Tool Support Bracket. No. 6. Double-Reduction Gear Shaft. 3. Examples (nine).

\section{Bolt Design}

1. Principles: Failure of Bolts, Tightening Nuts, Mild Steel or High Tensile Bolts, The Design of Bolts, The Loading of Bolted Components. 2. Designs: No. 1. Bolts for Crane Drum Bearing Bracket. No. 2. Bolts for Planing Machine Column. No. 3. Bolted Wall Bracket. No. 4. Machine Thrust Bracket. No. 5. Bolts for Diesel Connecting Rod. 3. Examples (five).

\section{Cylinders and Struts}

1. Cylinder Design, Principles: Thin Cylinders, Thick Cylinders, Design Considerations, Cylinders from Cold Drawn Tubes. 2. Struts, Principles: Notation, Short Struts, Long Struts, Intermediate Struts. 3. Designs: No. 1. Hydraulic Cylinder. No. 2. Hydraulic Jigger. No. 3. The 'Beanstalk'. No. 4. Determination of Force Fit Allowance for Shaft Mounted Disc. 4. Examples (eleven). 
1. Principles: The Function of Springs, Coiled Springs, Conical Disc Springs, Leaf Springs. 2. Designs : No. 1. Tension Spring. No. 2. Compression Spring for Centrifugal Trip Motion. No. 3. Return Spring for Ratchetting Mechanism. No. 4. Replacement Spring of Square Section for Design No. 3. No. 5. Spiral Spring for Return Lever. No. 6. Leaf Spring for Centrifugal Clutch. No. 7. Laminated Spring for Road Trailer. 3. Examples (seven).

\section{Power Transmission by Screws}

1. Principles: The Screw Pair, Thread Forms, The Strength of the Screw. 2. Designs : No. 1. Power Screw for Crane Jib. No. 2. Screw Flypress. No. 3. Geared Tension Screw. No. 4. Screw Operated Cross Head. No. 5. Planing Machine Screw. 3. Examples (five).

\section{Rotating Components}

1. Principles : Rotary Motion, More Complex Forms of Rotating Components, Safety Precautions, Notation and Formulae. 2. Designs: No. 1. The Windermere Ferry. No. 2. Disc Brake Dynamometer. No. 3. Experimental Gyroscope. 3. Examples (nine).

XV The Design Analysis of a Shaping Machine

1. Specification. 2. Extent of the Analysis. 3. The V-Belt Drive.

4. The Clutch. 5. The Link Motion. 6. Dynamic Considerations.

7. Stress Analysis of the Link Components. 8. Comment.

9. Appearance and Ergonomic Considerations. 10. Examples (three).

REFERENCES 


\section{Tables}

I.1. Properties of Metals

page

I.2. Physical Properties of Moulded Plastics 14

IV.1. Theoretical Stress Concentration Factors 59

V.1. Square Parallel Keys, Keyways and Keybars 66

V.2. Rectangular Parallel Keys, Keyways and Keybars 68

V.3. Rectangular Taper Keys and Keyways $\quad 70$

V.4. Polymer High-temperature Applications 73

V.5. Circular Hollow Sections 77

V.6. Rectangular Hollow Sections $\quad 79$

V.7. Standard V-Belts, Nominal Dimensions 81

V.8. Standard V-Belts, Horse Power Ratings 84

V.9. Standard V-Belts, Dimensions and Recommendations 85

V.10. Bearings, Ball Journal and Magneto 88

V.11. Bearings, Angular Contact and Duplex 89

V.12. Bearings, Parallel-Roller and Needle-Roller 90

V.13. Bearings, Thrust 91

V.14. Bearing Closures 102

V.15. Selected British Standards 108

IX.1. Torsion Factors for Rectangular Shafts 189

XI.1. Cylinders, $d / t$ Ratio 244

XI.2. Strut Materials, Rankine Constants 250

XII.1. Springs, Values of $\mu \quad 279$

XII.2. Springs, Values of $\lambda_{1} \quad 280$

XII.3. Springs, Values of $G \quad 281$

XII.4. Springs, Disc, Main Dimensions 288

XII.5. Springs, Deflections in Type B 289

XIV.1. Disc Brake Temperatures 372

XV.1. Shaping Machine Cutting Speeds 401

XV.2. Shaping Machine Velocity and Acceleration Values 404

XV.3. Shaping Machine Summary of Values 430 